\title{
The Scientific Basis of Migraine Management
}

\author{
W.J. Becker
}

Can. J. Neurol. Sci. 1999; 26: Suppl. 3-S1

"The Scientific Basis of Migraine Management" was the name given to a symposium held at Lake Louise, Alberta on February 13th and 14th, 1999. Manuscripts submitted by the speakers at the symposium are published in this supplement.

Migraine therapy has evolved considerably from the days when Edward Flatau ${ }^{1}$ published his comprehensive review on headache, "Die Migräne", in 1912. In true Borgia tradition, he recommended the subcutaneous application of arsenic in several series of thirty injections per year for migraine.

This symposium illustrates how far migraine treatment has come since that time, and also how much more rapidly our knowledge is increasing. For example, at the time of publication of "Die Migräne" in 1912, arsenic had been used for migraine therapy for over 100 years. Now every year or two brings an important new concept, or the marketing of a new treatment for migraine.

The topics in this symposium reflect our increasing knowledge about migraine, and "where the action is". Our increasing understanding of the biology of serotonin receptors is fuelling the development of new drugs. Our increasing understanding of the pathophysiology of migraine in general, and of craniofacial pain mechanisms, holds the promise of whole new avenues of migraine therapeutic approaches in the future.

The explosion of new symptomatic drug treatments for migraine which has followed the introduction of sumatriptan in the Canadian market in 1992, has made it necessary to develop innovative ways to evaluate the results of clinical trials, and compare different drugs. These issues are dealt with in detail by Dr P Goadsby in this supplement.

Unfortunately, our understanding of the mechanisms involved in migraine prophylactic drug therapy have not kept pace with our new knowledge in symptomatic migraine therapy. The evidence base for migraine prophylactic drug therapy is still far too small, and more research is needed. In a recent review, for example, ${ }^{2}$ there was considered to be no scientific evidence for the migraine prophylactic effectiveness for a drug that was the prophylactic drug of choice of almost $3 \%$ of American neurologists and 5\% of American family physicians.

Despite the current focus on migraine drug therapy, which is driven in part by intense industry interest in this potentially large drug market, psychological treatments for migraine including relaxation therapy and biofeedback, remain greatly underutilized. Dr P McGrath reviews the evidence base for many of these in this supplement.

Our ultimate goal in understanding migraine will likely eventually come from genetic studies. Great excitement was produced in the migraine community by the finding that a rare and complex migraine syndrome, familial hemiplegic migraine, was produced by a mutation in a calcium channel gene. ${ }^{3,4}$ The genetic basis of the more common migraine syndromes remains to be elucidated, and our current knowledge in this area is reviewed by Dr K Gardner in this supplement.

Our understanding of the scientific basis of migraine has come a long way, and has already had important therapeutic implications. There is still a long way to go, however, and it is hoped that this supplement will encourage further interest and research in this area.

\section{REFERENCES}

1. Isler H. Historical background. In: Olesen J, Tfelt-Hansen P, Welch KMA eds. The Headaches. New York: Raven Press Ltd, 1993:1-8.

2. Ramadan NM, Schultz LL, Gilkey SJ. Migraine prophylactic drugs: proof of efficacy, utilization and cost. Cephalalgia 1997;17:7380.

3. Joutel A, Bousser MG, Biousse V et al. A gene for familial hemiplegic migraine maps to chromosome 19. Nature Genetics 1993;5:40-45.

4. Ophoff RA, Terwindt GM, Vergouwe MN et al. Familial hemiplegic migraine and episodic ataxia Type- 2 are caused by mutations in the $\mathrm{Ca}^{+}{ }^{+}$channel gene CACNL1A4. Cell 1996;87:543-552.
From the University of Calgary, Calgary, Alberta, Canada

Reprint requests to: W J Becker, 12th Floor, Neurology, Foothills Hospital, 1403 29th Street NW, Calgary, Alberta T2N 2T9 